$\xi=$

\title{
Shiga-toxin producing Escherichia coli (STEC) and other enterobacteriaceae associated with ready-to-eat salad
}

\author{
Iyekhoetin Matthew Omoruyi*, Ufuoma Akpezi Orieruo \\ Department of Basic Sciences (Microbiology option), Faculty of Basic and Applied Sciences, \\ Benson Idahosa University, P.M.B. 1100, Benin City, Edo State, Nigeria \\ *Corresponding author E-mail: iomoruyi@biu.edu.ng
}

\begin{abstract}
Ready-to-eat (RTE) salads sold in Nigeria are poorly delineated sources of human exposure to pathogenic microorganisms. In this study, we investigated the current situation in Benin City, Edo state, Nigeria. Twenty-four samples of RTE salad were obtained from different open markets, and the presence of Shiga toxin-producing Escherichia coli (STEC) and other enterobacteriaceae were determined by established methods using both selective and chromogenic agars. All RTE salad samples were found to habour Escherichia coli while 16.7\% were further confirmed for the presence of STEC. Other Enterobacteriaceae present included Klebsiella spp, Proteus spp, Enterobacter spp, Serratia spp and Salmonella spp. The antibiogramic profile revealed that all bacterial isolates obtained were resistant to augmentin and amoxicillin while only $11.1 \%$ were resistant to ciprofloxacin and ofloxacin. The percentage resistance for the Shiga-toxin producing strains of E. coli was $60 \%$ while Serratia showed resistance to all the antibiotics used. The results of this study showed that RTE salad sold in Benin City, Edo State, Nigeria could be a source of public health concern, and effort should be made to avert possible outbreak.
\end{abstract}

Keywords: Salad; Outbreak; Shiga Toxin-Producing E. coli; Enterobacteriaceae; Public Health.

\section{Introduction}

Ready-to-eat (RTE) foods are food products that do not require further processing to ensure safety and palatability prior to consumption. Examples of RTE food include lunch-on meats, salad, bakery products and cheeses. Salads are made with fresh vegetables such as lettuce, spinach, carrot, cabbage, cucumber, and sprout and are known as one of the important sources of vitamins, nutrients and fiber (Grant, 2008). The demand for fresh vegetables in Nigeria is on the increase as people are now more concerned with healthy lifestyle and balanced diet (Warriner et al., 2009; Olaimat and Holley, 2012). In addition to the beneficial health effect of salad, they could be sources of outbreak of several infections and illnesses. Also, the outbreaks of food infections associated with RTE salad are said to be on the increase (Oluwatosin and Elna, 2012). In September 2006, pre-packaged fresh salad were recalled by the Food and Drug Administration (FDA) in the United States of America (USA) as a result of an Escherichia coli outbreak in California, USA (Oluwatosin and Elna, 2012). Also in the same month there was an E. coli 0157 : $\mathrm{H} 7$ outbreak linked to lettuce from Taco Bell restaurants in Northern USA (Oluwatosin and Elna, 2012). Similarly, in 2011, Germany reported a nationwide outbreak of haemolytic uremic syndrome (HUS) caused by Shiga toxin-producing E. coli (STEC). This outbreak was associated with the consumption of fresh salad vegetables which resulted in 54 deaths (Frank et al., 2011). The Public Health Agency of Canada also reported in June 2011, one suspected case of E. coli O104 infection (without HUS), with travel history to Northern Germany and with link to a confirmed case of E. coli O104 infection in Germany.

Additionally, the occurrence of microorganisms especially the enterobacteriaceae in RTE salad is an indication of the sanitary conditions of the processing process as well as the microbiological condition of raw product at the time of processing (Nguyen and Carlin, 1994). Other factors that could influence the proliferation of microorganisms in RTE salad include the hygiene of the personnel involved in the preparation, the utensils, equipment, storage pattern and the processing environment. These factors may lead to a rise in the number of pathogens in salad at infectious doses.

STEC is associated with haemorrhagic colitis (HC), haemolyticuremic syndrome (HUS) and renal failure in children (Coombes et al., 2008). Although most studies have shown that outbreaks of HC and HUS are associated with E. coli O157:H7 (Pradel et al., 2001; 2008), some studies have also reported high prevalence of non-O157 and O157: H-(non-motile) serotypes in human diseases and from animals and related food products (Coombes et al., 2008; Pradel et al., 2001)

Many types of food have been implicated in STEC outbreaks: undercooked bovine meat products (minced meat, hamburgers), fresh produce such as lettuce, bean sprouts and spinach, unpasteurized apple cider, and raw milk. STEC outbreaks have also been waterborne, owing to faecally contaminated drinking-water or contaminated water during swimming (WHO, 2011).

Considering the potential public health impact of these isolates (STEC and the Enterobacteriaceae), this study was aimed at isolating Shiga-toxin producing strains of Escherichia coli and other Enterobacteriaceae of public health concern from RTE salad sold in Benin City, Edo State, Nigeria, and to determine their antimicrobial sensitivity pattern. 


\section{Materials and methods}

\subsection{Materials}

The Nutrient agar, Eosin methyl blue (EMB) agar, Muller Hinton agar and MacConkey agar used in this study were obtained from Titan Biotech Ltd (Rajasthan, India), while the CHROMagar STEC base was obtained from CHROMagar (Paris, France).

\subsection{Sample collection}

Twenty-four samples of ready-to-eat salad were obtained from two major markets (Oba and Eki-Osa) in Benin City, Edo State, Nigeria. All samples were obtained between January and February 2016.

\subsection{Microbiological analysis}

The mean coliform and mean enterobacteriaceae counts were determined as previously reported (Omoruyi et al., 2011). Briefly, $25 \mathrm{~g}$ of salad samples were placed in $225 \mathrm{ml}$ of peptone water, following which serial dilutions were made. One milliliter each of the serial dilutions $\left(4^{\text {th }}\right.$ and $\left.5^{\text {th }}\right)$ was transferred to already prepared Eosin EMB, MacConkey agar and Nutrient agar plates. The respective agar plates were then incubated in triplicates at $37^{\circ} \mathrm{C}$ for 24hours.

\subsection{Identification of bacterial isolates}

Clearly distinct colonies were identified based on their cultural, morphological and biochemical characteristics, principally characteristic of the Enterobacteriaceae family. Pure cultures of all colonies exhibiting typically dark colonies with green metallic sheen on EMB agar and pink colonies on MacConkey agar were subcultured and re-plated on CHROMagar STEC base. E. coli strains habouring the shiga-toxin gene were noted for the mauve colouration (Figure 1) while other enterobacteriaceae were either inhibited or were indicated with colourless to bluish colouration.

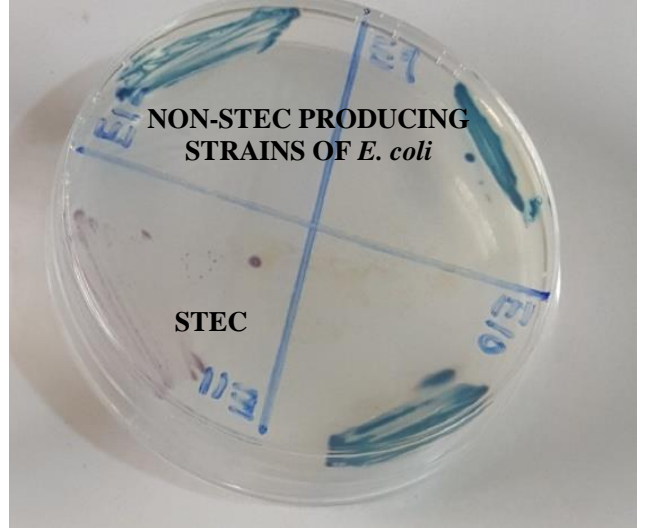

Fig. 1: Shiga-Toxin Producing E. coli on Chromagar STEC Base.

\subsection{Antibiotic sensitivity profile}

The antibiogramic activities of the isolates were determined as previously reported (Iyekhoetin et al., 2011). Briefly, bacterial isolates were inoculated into sterile nutrient broth in test tubes and incubated for $24 \mathrm{hrs}$ at $37^{\circ} \mathrm{C}$. After $24 \mathrm{hrs}$ isolates were streaked on already solidified Muller Hinton agar plates. Antibiotics disk were immediately placed on the streaked agar plates with forceps which were then incubated for $24 \mathrm{hrs}$. Zone of inhibition indicated sensitivity of the isolates to the antibiotics, while absence of a clear zone indicated resistance of the organisms to the antibiotics.

\section{Results and discussion}

Shiga-toxin producing Escherichia coli (STEC) and other enterobacteriaceae are well known human pathogens globally. The sources of these pathogen of public health concern include beef, meat product, chicken, ready-to-eat salad etc. Fresh meat and meat product have previously been screened for the presence of STEC (Olatoye et al., 2012; Reuben and Gyar, 2015; Kabiru et al., 2015; Enabulele and Uraih, 2009). However, the occurrence of STEC in RTE salad has gained little or no attention especially in developing countries. To this end, the current study was aimed at investigating the current situation in Benin City, Edo State, Nigeria.

The results of the current study showed that RTE salad sold in Benin City, Edo State, Nigeria, are sources of human exposure to pathogenic microorganisms. All RTE salad samples obtained from both markets (Oba and Eki-Osa) had mean coliform and mean enterobacteriaceae counts ranging from 0.9 to $7.1 \times 10^{6}$ and 0.2 to $12.2 \times 10^{6} \mathrm{cfu} / \mathrm{mL}$ respectively (Table 1 ).

Table 1: Mean Coliform Counts (MCCs) and Mean Enterobacteriaceae Counts (MECs) Of Ready-To-Eat Salad

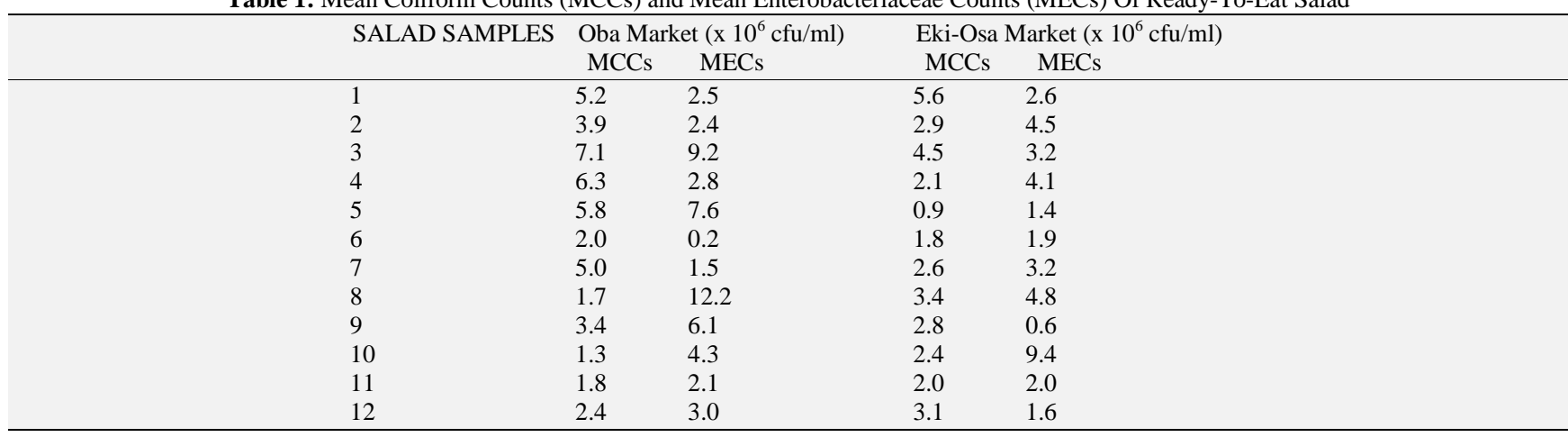

A total of thirty-one different strains of $E$. coli were obtained from all ready-to-eat salad from all sampling locations. Two of these $E$. coli strains were further confirmed to be STEC (Figure 1). Interestingly, both $E$. coli strains habouring the shiga-toxin gene obtained in this study were from the same sampling market (Oba market). Other Enterobacteriaceae present in all salad samples included Klebsiella spp, Enterobacter spp, Serratia spp, Salmonella spp and Proteus spp.

The antibiogramic activities of the isolates showed that all bacterial isolates were resistant to augmentin and amoxicillin. The cumulative antibiotic resistant profile of the isolates is shown in Table 2 . The highest resistance (100\%) was obtained with amoxicillin and augmentin, while the least was obtained with ciprofloxacin 
and ofloxacin [11.1\%] (Table 2). The percentage resistance for the shiga-toxin producing E. coli was $(60 \%)$. Also the suspected en- terobacteriaceae, Serratia showed resistance to all the antibiotics used.

Table 2: Antimicrobial Susceptibility of Bacterial Isolates to Commonly Used Antibiotics

\begin{tabular}{|c|c|c|c|c|c|c|c|c|c|}
\hline \multirow{2}{*}{$\frac{\text { Isolates }}{\text { Antibiotics }}$} & \multirow[t]{2}{*}{1} & \multirow[t]{2}{*}{2} & \multirow[t]{2}{*}{3} & 4 & 5 & 6 & 7 & 8 & 9 \\
\hline & & & & \multicolumn{6}{|c|}{ ZONES OF INHIBITION (mm) } \\
\hline $\mathrm{CN}$ & $\mathrm{R}$ & 15 & 15 & 10 & 15 & 15 & $\mathrm{R}$ & $\mathrm{R}$ & 20 \\
\hline $\mathrm{AU}$ & $\mathrm{R}$ & $\mathrm{R}$ & $\mathrm{R}$ & $\mathrm{R}$ & $\mathrm{R}$ & $\mathrm{R}$ & $\mathrm{R}$ & $\mathrm{R}$ & $\mathrm{R}$ \\
\hline $\mathrm{AM}$ & $\mathrm{R}$ & $\mathrm{R}$ & $\mathrm{R}$ & $\mathrm{R}$ & $\mathrm{R}$ & $\mathrm{R}$ & $\mathrm{R}$ & $\mathrm{R}$ & $\mathrm{R}$ \\
\hline CPX & 25 & 30 & 20 & 20 & 20 & 20 & $\mathrm{R}$ & 25 & 20 \\
\hline SP & 20 & 20 & 20 & 15 & 20 & 25 & $\mathrm{R}$ & 20 & $\mathrm{R}$ \\
\hline $\mathrm{CH}$ & 25 & $\mathrm{R}$ & 20 & $\mathrm{R}$ & 20 & 25 & $\mathrm{R}$ & $\mathrm{R}$ & $\mathrm{R}$ \\
\hline SXT & $\mathrm{R}$ & $\mathrm{R}$ & 15 & $\mathrm{R}$ & 25 & 30 & $\mathrm{R}$ & $\mathrm{R}$ & $\mathrm{R}$ \\
\hline S & $\mathrm{R}$ & $\mathrm{R}$ & 20 & $\mathrm{R}$ & 10 & 25 & $\mathrm{R}$ & $\mathrm{R}$ & $\mathrm{R}$ \\
\hline OFX & 25 & 20 & 20 & 10 & 15 & 15 & $\mathrm{R}$ & 15 & 20 \\
\hline PEF & $\mathrm{R}$ & 20 & 15 & 20 & 15 & 20 & $\mathrm{R}$ & 15 & 20 \\
\hline$\%$ Resistance & 60 & 50 & 20 & 50 & 20 & 20 & 100 & 60 & 60 \\
\hline
\end{tabular}

Key: CPX: Ciprofloxacin; AM: Amoxicillin, AU: Augmentin; CN: Gentamicin; OFX: Ofloxacin; PEF: Pefloxacin; S: Streptomycin; SXT: Septrin; 1: Klebsiella spp 1; 2: Klebsiella spp 2; 3: Proteus spp; 4: E. coli 1; 5: Enterobacter spp; 6: E. coli 2; 7: Serratia spp; 8: Salmonella spp; 9: Shiga-toxin producing strain of E. coli.

The results of the current study showed that RTE salads sold in Benin City, Edo state, Nigeria are not free of coliform, enterobacteriaceae and STEC. The presence of coliform in ready- to- eat salad samples is an indication of faecal contaminants either from the food handlers, chopping boards or cutting knife (Oguwike et al., 2014)

The prevalence of E. coli strains in ready-to-eat salad was (100\%), and is in keeping (although slightly higher) with the results of Enabulele and Uraih (2009), who reported the prevalence of $E$. coli in RTE vegetables (lettuce, cabbage, tomatoes) to be $83.33 \%$. The presence of Escherichia coli in RTE salad is of concern as Escherichia coli are well known food-borne pathogen which is able to cause food-borne illness globally.

The presence of E. coli in salad and vegetables could be attributed to a number of factors. For example, a number of vegetable farmers in developing countries like Nigeria use cow dungs and poultry waste as manures, all of which have been reported as carrier of both faecal coliform and STEC. Another likely source of contamination with this organism is the vehicles on which the vegetables are transported to the various sales point. It has been reported that vegetables are transported using the same vehicles used in transporting cattle from one part of the country to the other, which could also be a source of concern.

The result obtained with STEC in this study is similar with the results of Puspanadan et al., 2013; Khatib and Khawaja 2015 and Somayeh et al., 2013. In one of these studies, Khatib and Khawaja (2015) found 4.8\% (7 out of 145) of Lebanese fresh vegetables to contain STEC. The fresh vegetables included lettuce, tomato, cucumber and radish. Similarly, Somayeh et al., (2013) found 8\% (8 out of 100) of ready to eat vegetables from a city in Iran to contain STEC. In both studies, the percentage occurrence of STEC was lower than that obtained in the current study. However, Puspanadan et al., (2013) found a slightly higher percentage (18.5) of STEC from Malaysia than that reported in the current study.

The result of this study is also contrary to the report of Enabulele and Uriah (2009), who reported zero incidence of STEC from vegetables sold in Benin City, Edo State, Nigeria.

The high occurrence of Enterobacteriaceae is supported by Sproston et al. (2006). These organisms are mainly found in the intestinal tracts of humans and animals, and are mostly pathogenic to humans. Faecal materials, decaying matter, contaminated water, selling environment and poor handling are some factors that could contribute to the high numbers of enterobacteriaceae.

In conclusion, the low level of sanitary practices amongst food handlers as well as lack of adequate data on outbreaks of infections could aid the spread of pathogenic organisms without detection. Hence, it is important to take seriously the isolation of these organisms in RTE salad from Benin City, Edo State, Nigeria. Consequently, it is recommended that food handlers wash food items using appropriate food grade anti-microbial as well as clean materials needed for the preparation of RTE salad prior to con- sumption. Finally, RTE salad should not be carried using the same containers used for fresh meat to avoid cross contamination.

\section{Conflict of interest}

The authors declare that there are no potential conflicts of interest

\section{References}

[1] Coombes, K.B., Wickham, E.M., Mascarenhas, M., Gruenheid, S., Finlay, B.B. and Karmali, A.M, (2008). Molecular analysis as an aid to assess the public health risk of non-O157 shiga toxinproducing Escherichiacoli strains. Applied Environmental Microbiology. 7: 2153 - 2160.http://dx.doi.org/10.1128/AEM.02566-07.

[2] Enabulele, S.A., and Uraih, N. (2009). EnterohamohhagicEscherichiacoli 0157; $\mathrm{H} 7$ prevalance in meat and vegetable sold in Benin CityNigeria. African Journal of MicrobiologyResearch. 3:276-279.

[3] Frank, C., Dirk, W.D., Jakob, P., Cramer, M.D. and Mona, A. (2011). Epidemic profile of shiga- toxin producing Escherichiacoli 0104; H4 outbreak in Germany. Journal of Medicine. 365:17711780.

[4] Grant, G. (2008). Microbial quality of poultry meat. Review Brazillian Journal of Poultry Sciences. 6:135-142.

[5] Iyekhoetin, O.M., Nnanna, I.I., Blessing, O.I. and Idowu, B.O. (2011). Antibiograms and mutagenicity evaluation of hospital wastewaters from University of Benin Teaching Hospital (UBTH), Benin City. European Journal of Scientific Research. 52(2) : 226235.

[6] Kabiru, K.M., Bello, M., Kabir, J., Grande,L. and Morabito,S. (2015) Detection of Pathogenic Escherichia coli in Samples Collected at an Abattoir in Zaria, Nigeria and at Different Points in the Surrounding Environment. International Journal of Environmental Research and Public Health. 12: 679691.http://dx.doi.org/10.3390/ijerph120100679.

[7] Khatib, A.O and Khawaja, G. (2015) Shiga Toxin-Producing E. coli (STEC) Associated with Lebanese Fresh Produce. International Journal of Current Microbiology and Applied Sciences; 4: 481-496.

[8] Nguyen, C. and Carlin, F. (1994). The microbiology of minimal processed fresh fruits and vegetables. Critical Review of Food Science Nutrition; 34:371401http://dx.doi.org/10.1080/10408399409527668.

[9] Olaimat, A.N. and Holley, R.A. (2012). Factors influencing the microbial safety of fresh produce. Review Food Microbiology; 32:119.http://dx.doi.org/10.1016/j.fm.2012.04.016.

[10] Olatoye, I.O., Amosun, E.A and Ogundipe, G.A (2012). Multidrug Resistant Escherichia coli O157 Contamination of Beef and Chicken in Municipal Abattoirs of Southwest Nigeria. Nature and Science; 10:125-132.

[11] Oluwatosin, A.I. and Elna M.B. (2012) Irrigation water and microbiological safety of fresh produce; South African as a case study. African Journal of Agricultural Research; 7:4848-4857

[12] [12] Oguwike, F. N., Offor, C. C., Nwadighoha, A. N. and Ebede, S. O. (2014). Evaluation of efficacy of cabbage juice (Brassica OleraceaLinne) as potential antiulcer agent and its effect on the 
haemostatic mechanism of male albino wistar rats. Journal of Dental and Medical Sciences; 13: 92- 97.

[13] [13] Omoruyi, I.M., Wogu, M.D., Eraga, E.M. (2011). Bacteriological quality of beef-contact surfaces, air microflora and wastewaters from major abattoirs in Benin City, Southern Nigeria. International Journal of Biosciences 1(3): 57-62.

[14] [14] Pradel, N., Bertin, Y., Martin, C. and Livrelli, V. (2008). Molecular analysis of shiga toxin-Producing Escherichiacoli strains isolated from hemolytic uremic syndrome patients and dairy samples in France. Applied Environmental Microbiology; 74:2118 2128.

[15] Pradel, N., Boukhors, K., Bertin, Y., Forestier, C., Martin, C. and Livrelli, V. (2001). Heterogeneity of shiga toxin-producing Escherichiacoli strains isolated from hemolytic-uremic syndrome patients, cattle, and food samples in central France. Applied Environmental Microbiology; 67: $2460 \quad-\quad 2468$. http://dx.doi.org/10.1128/AEM.67.6.2460-2468.2001.

[16] Puspanadan, L. Y. , Goh, S. G., Kuan, C. H., Chang, W. S., Lye, Y L., John, Y. H., Rukayadi, Y., Yoshitsugu, N., Nishibuchi, M. and Son, R. (2013) Quantitative detection and characterization of Shiga toxin-producing Escherichia coli $\mathrm{O} 157$ and non-O157 in raw vegetables by MPN-PCR in Malaysia. International Food Research Journal; 20:3313-3317.

[17] Reuben,C.R. and Gyar, S.D. (2015). Isolation and Antibiogram of Shiga Toxin-Producing Escherichia coli O157:H7 from Diarrhoeic HIV/AIDS Patients in Lafia, Central Nigeria. International Research Journal of Microbiology; 6:20-26.

[18] Somayeh, M., Siavosh, S.A. and Mohammade, A. (2013). Shiga Toxin-Producing Escherichia Coli Isolated from Lettuce Samples in Tehran, Iran. Jundishapur Journal of Microbiology; 7:126-131.

[19] Sproston, E., Macre, L., Ogdan, M. and Wilson, D. (2006). Slugs: Potential novel victor of Escherichia coli 0157. Applied and Environmental Microbiology; 1:144 149http://dx.doi.org/10.1128/AEM.72.1.144-149.2006.

[20] Warriner, K., Huber, A., Namvar, A., Fan, W. and Dunfield, K (2009).Recent Advances in the Microbial Safety of Fresh Fruits and Vegetables. Nutrition Research Journal; 5-155160.http://dx.doi.org/10.1016/s1043-4526(09)57004-0.

[21] World Health Organization, (2011). Public health review of the enterohaemorrhagicEscherichiacoli outbreak in Germany. http://www.euro.who.int/ehec. 